\title{
EFFECT OF PROCESS PARAMETERS ON ANGULAR DISTORTION OF GMAW WELDED C45 PLATES
}

\author{
Rishav Kumar Jha ${ }^{1}$, Ajay Kumar ${ }^{2}$, Anubhav Chakraborty ${ }^{3}$, Pradeep Khanna ${ }^{4}$

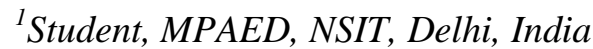 \\ ${ }^{2}$ Student, MPAED, NSIT, Delhi, India \\ ${ }^{3}$ Student, MPAED, NSIT, Delhi, India \\ ${ }^{4}$ Associate Professor, MPAED, NSIT, Delhi, India
}

\begin{abstract}
Gas Metal Arc welding process is one of the most expensively used arc welding process because of many advantages it offers like capability of welding a large variety of materials, adaptability to automation and versatility to weld out of position welds. Distortions in welded structures is inhabitable because of fast heating and cooling cycles resulting in non-uniform distribution of stresses which cause distortion. Out of different type of distortion angular distortion is the most prominent and results in dimensional change, mis match in the assembly and poor appearance. An investigation is thus carried out to analysis its generation under different combination of independently controllable input parameters. The input parameters found of importance are welding current, voltage, nozzle to plate distance and welding speed. Statistical technique of design of matrix was used to decide the no. of experiments. Design expert was in use to carry out the ANOVA analysis and to develop a mathematical model. Significance of model was tested and closeness of predicted and actual value by using a develop model were investigated by using scattered diagram. Response surface methodology was used to optimize the design.
\end{abstract}

Keywords: - Angular distortion, design of experiments, ANOVA, Mathematical model $* * *$

\section{INTRODUCTION}

The gas metal arc welding (GMAW) process is a popular welding process today and is favored by welding fabricators, owing to its versatility. Despite its seventy years of history, research and development continue to provide improvements to this process, and the efforts have been rewarded with high quality results[2]. During the heating and cooling cycle of the welding process, the weld metal experiences continuous expansion and contraction which causes distortion. Many factors such as physical andmechanical properties of material that change as heat is applied,affect shrinkage of the metal and lead to distortion. Angular distortion or out-of-plane distortion is one such defect that makes the workpiece distort in angular directions around the weld interface[3].

Various techniques are employed to reduce angular distortion such as prevention of over weld, use of intermittent welding and using as few weld passes as possible.

In this experimental work, mathematical models were developed to analyze the effect of different process parameters, viz. Welding speed, Voltage, Wire Feed Rate and Nozzle to Plate Distance, on Angular Distortion.

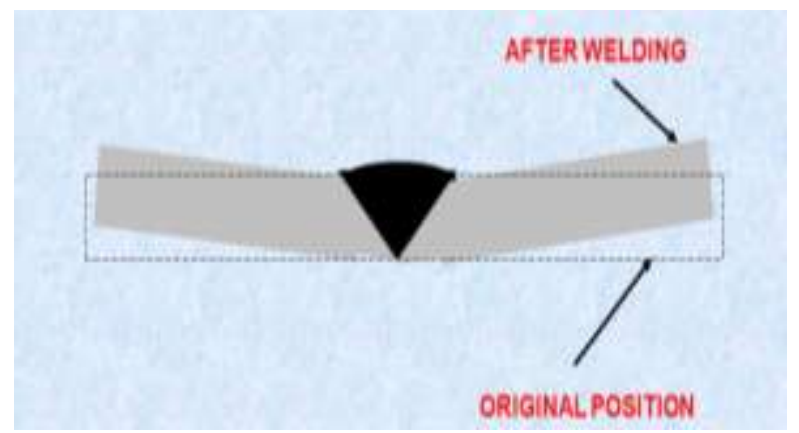

Fig 1: Schematic of angular distortion [1]

\section{EXPERIMENTAL PROCEDURE}

Statistical technique was used to determine the number of experiments to be conducted. In the present case, a statistical technique software,Design Expert 11 was used. Central composite face-centered technique was adopted to decide the number of experiments. A total of 30 experiments were conducted $\left(2^{4}+2 \times 4+6=30\right)$. Response surface methodology was used to optimize the design.

\section{EXPERIMENTAL SETUP}

The experiments were conducted on a MIG welding power source with a rated capacity of 400 amps and flat V-I characteristics. The plates were cut in size $150 \mathrm{~mm} \times 100 \mathrm{~mm}$ each. In order to eliminate variation in quality due to welder's skill and to achieve reproducibility, a variable frequency controlled mechanized welding unit was used 
which could give a stepless control of welding speed between a range of $0 \mathrm{~cm} / \mathrm{min}$ to $50 \mathrm{~cm} / \mathrm{min}$. The radial arm mounted on the system can facilitate the movement of welding torch in $\mathrm{y}$ and $\mathrm{z}$ directions to accommodate different sizes of workpieces. The complete experimental setup is shown in fig 2 .

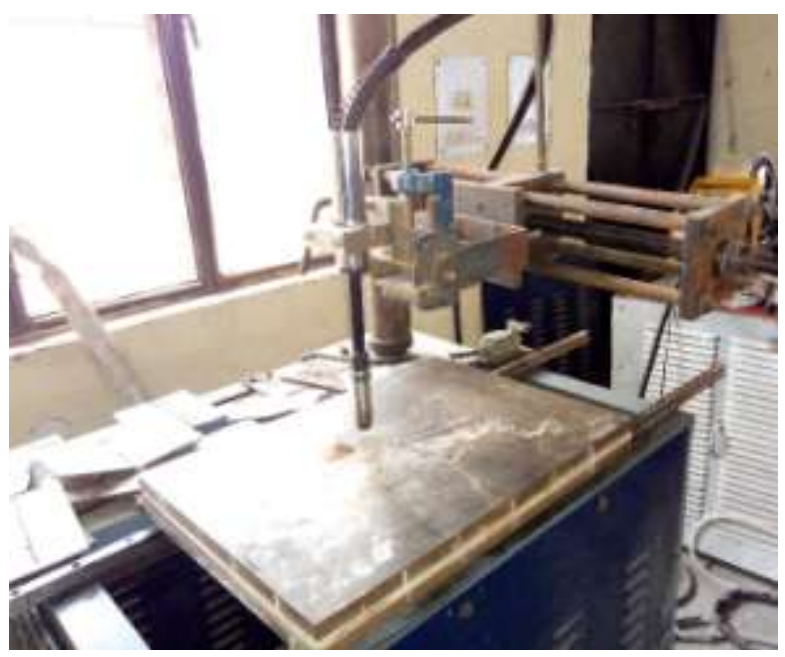

Fig 2: Experimental setup

\section{PLAN OF INVESTIGATION}

The investigation was carried out as per the following steps:

1. Identification of important welding parameters.

2. Finding the working limits of these parameters

3. Developing the design matrix
4. Conducting the experiment according to the design matrix

5. Recording the response

6. Developing the mathematical model

7. Testing the adequacy of the mathematical model.

\subsection{Identification of Important Welding Parameters}

In order to investigate the effect of angular distortion, the following different independent parameters were identified during the experiment, viz. Nozzle to plate distance $(\mathrm{N})$, Wire feed $\operatorname{rate}(\mathrm{W})$, Welding $\operatorname{speed}(\mathrm{S})$ andVoltage(V). All the parameters were carefully adjusted to complete the weld joint in a single pass.

\subsection{Finding the Working Limits of these Parameters}

To find the working limits of the different parameters, trial runs were conducted by varying one of the process parameters and keeping the others constant[4]. The limits of the parameters were decided upon by inspecting the bead formed on the joint for smooth appearance and with minimal defects. The upper limit was coded as +1 and lower limit as -1 .The intermediate value was taken tobe the algebraic mean of the upper and lower limit values, and coded as 0 .

Table 1: Process parameters and their limits

\begin{tabular}{|l|l|l|l|l|l|}
\hline \multirow{2}{*}{ Process Parameters } & \multirow{2}{*}{ Units } & \multirow{2}{*}{ Notation } & Limits & $\mathbf{+ 1}$ \\
\hline Wire Feed Rate & $\mathrm{m} / \mathrm{min}$ & $\mathrm{W}$ & 1.7 & 2.1 & 2.5 \\
\hline Welding Voltage & volts & $\mathrm{V}$ & 16 & 20 & 24 \\
\hline Welding Speed & $\mathrm{cm} / \mathrm{min}$ & $\mathrm{S}$ & 20 & 30 & 40 \\
\hline $\begin{array}{l}\text { Nozzle to Plate } \\
\text { distance }\end{array}$ & $\mathrm{mm}$ & $\mathrm{N}$ & 10 & 15 & 20 \\
\hline
\end{tabular}

\subsection{Developing the Design Matrix}

Table 2: Design matrix and observed values of angular distortion $(\alpha)$

\begin{tabular}{|l|l|l|l|l|l|}
\hline Run & W & S & V & N & a (degrees) \\
\hline 1 & 1.7 & 40 & 24 & 20 & 0.46 \\
\hline 2 & 2.1 & 30 & 20 & 15 & 0.98 \\
\hline 3 & 1.7 & 40 & 16 & 20 & 0.57 \\
\hline 4 & 2.1 & 30 & 20 & 15 & 1.01 \\
\hline 5 & 2.5 & 40 & 16 & 20 & 1.86 \\
\hline 6 & 2.5 & 40 & 16 & 10 & 1.29 \\
\hline 7 & 2.5 & 20 & 24 & 20 & 0.71 \\
\hline 8 & 2.5 & 30 & 20 & 15 & 1.43 \\
\hline 9 & 2.1 & 30 & 20 & 15 & 1.04 \\
\hline 10 & 2.1 & 30 & 16 & 15 & 1.97 \\
\hline 11 & 2.1 & 30 & 20 & 20 & 1.12 \\
\hline
\end{tabular}




\begin{tabular}{|l|l|l|l|l|l|}
\hline 12 & 2.5 & 20 & 16 & 20 & 2.21 \\
\hline 13 & 2.1 & 40 & 20 & 15 & 0.14 \\
\hline 14 & 2.1 & 30 & 24 & 15 & 1.25 \\
\hline 15 & 2.1 & 30 & 20 & 10 & 0.79 \\
\hline 16 & 2.1 & 30 & 20 & 15 & 0.98 \\
\hline 17 & 1.7 & 30 & 20 & 15 & 1.02 \\
\hline 18 & 2.1 & 20 & 20 & 15 & 0.36 \\
\hline 19 & 1.7 & 20 & 24 & 20 & 0.58 \\
\hline 20 & 1.7 & 40 & 24 & 10 & 0.39 \\
\hline 21 & 1.7 & 20 & 16 & 20 & 1.61 \\
\hline 22 & 1.7 & 20 & 24 & 10 & 0.48 \\
\hline 23 & 2.5 & 40 & 24 & 10 & 1.05 \\
\hline 24 & 1.7 & 20 & 16 & 20 & 1.61 \\
\hline 25 & 2.1 & 30 & 20 & 15 & 0.95 \\
\hline 26 & 1.7 & 40 & 16 & 10 & 0.16 \\
\hline 27 & 2.1 & 30 & 24 & 15 & 1.04 \\
\hline 28 & 2.5 & 40 & 24 & 20 & 1.28 \\
\hline 29 & 2.5 & 20 & 16 & 10 & 0.45 \\
\hline 30 & 1.7 & 20 & 10 & 1.17 \\
\hline
\end{tabular}

A three-level, four-factors, central composite response surface design consisting of 30 sets of coded conditions was developed which is shown in Table 2. The design matrix comprises a full replication factorial design $2^{4}[=16]$ plus eight-star points and six center points. All welding parameters at the intermediate level $(0)$ constitute center points and combinations at either its lowest $(-1)$ or highest (+1) level with the other two parameters at the intermediate level constituting the star points. Thus the 30 experimental runs allowed the estimation of the linear, quadratic, and twoway interactive effects of the process parameters on the angular distortion[5, 6].

\subsection{Conducting the Experiment as per the Design}

\section{Matrix}

The experiment was conducted in accordance with the design matrix at random, to minimize the systematic errors in recording the response.

\subsection{Recording the Response}

The Angular distortion ( $\boldsymbol{\alpha})$ was measured using trigonometry. A typical distorted welded plate is shown in fig 3. The opposite surface of the weld plates was smoothened out with the help of grinding wheel to remove any roughness that might have been caused due to penetration of the weld. The pieces were then kept on a surface plate and the height $(\boldsymbol{h})$ up to which one side of the welded plate is raised was measured with the help of a Vernier height gauge as shown in fig 3 . If the width of one plate is represented as 'd', then,
$\operatorname{Sin} \theta=h / d$.

Three readings were taken randomly on each welded plate and the mean values of $\boldsymbol{\alpha}$ was measured, which is given in Table-2.

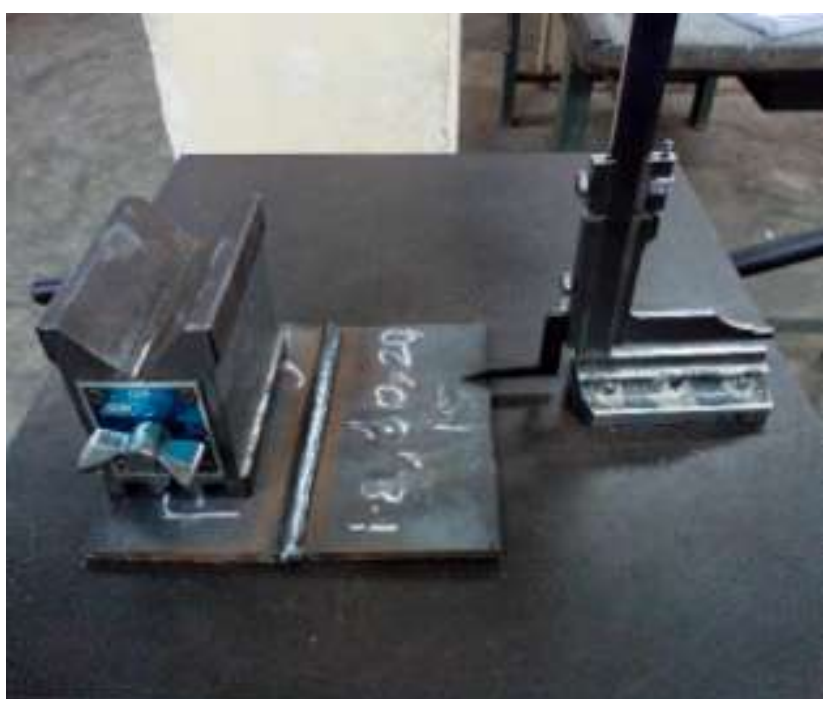

Fig 3: Angle measuring setup

\subsection{Developing the Mathematical Model}

The response surface function representing angular distortion, $\boldsymbol{\alpha}$, can be expressed as

$$
\alpha=f(N, W, S, V)
$$


The general mathematical equation can be written as follows:

Angular distortion $(\alpha)=b_{0}+b_{1} A+b_{2} B+b_{3} C+b_{4} D+$ $b_{12} A B+b_{13} A C+b_{14} A D+b_{23} B C+b_{24} B D+b_{34} C D+b_{11} A^{2}+$ $b_{22} B^{2}+b_{33} C^{2}+b_{44} D^{2}$

where $b_{0}$ is the free term of the regression equation, the coefficient $b_{1}, b_{2} \ldots b_{k}$ are linear terms, the coefficients $\mathrm{b}_{11}, \mathrm{~b}_{22}, \ldots . \mathrm{b}_{\mathrm{kk}}$ are quadratic terms and coefficients $\mathrm{b}_{12}, \mathrm{~b}_{13}, \ldots \mathrm{b}_{(\mathrm{k}-1) \mathrm{k}}$ are the interaction terms. Design Expert software deduced the following mathematical equation in coded terms relating angular distortion to the welding process parameters was used to calculate the coefficients and the mathematical equation developed is as follows.
4.7 Checking the Adequacy of the Mathematical

\section{Model}

All the values of input parameters and response obtained after conducting the experiment as per the design matrix were put in design expert software.[7] The results of the analysis carried out are presented in table-3 and table-4 respectively. Table-3 shows the ANOVA analysis of the developed model. It is evident that the developed model is significant with lack of errors not significant. The high value of $\mathrm{R}^{2}$ as shown in Table-4 further proves a closed fitness of the developed model. The scatter diagram shown in fig.4also confirms the adequacy of the model as the actual and predicted values like in close proximity.

\footnotetext{
$\alpha=1.01+0.3 A-0.11 B-0.32 C+0.17 D+0.17 A B-$

$0.18 A C+0.04 A D+0.23 B C-0.007 B D-0.08 C D+0.21 A^{2}-$ $0.76 B^{2}+0.59 C^{2}-0.06 D^{2}$
}

Table 3: ANOVA for the developed quadratic model

\begin{tabular}{|l|r|r|r|r|r|}
\hline \multicolumn{1}{|c|}{ Source } & $\begin{array}{c}\text { Sum of } \\
\text { Squares }\end{array}$ & df & $\begin{array}{c}\text { Mean } \\
\text { Square }\end{array}$ & F-value & p-value \\
\hline Model & 7.90 & 14 & 0.5643 & 264.80 & $<0.0001$ \\
\hline A-Wiqnificant \\
\hline A-WF & 1.65 & 1 & 1.65 & 774.31 & $<0.0001$ \\
\hline B-WELDING SPEED & 0.2178 & 1 & 0.2178 & 102.20 & $<0.0001$ \\
\hline C-VOLTAGE & 1.87 & 1 & 1.87 & 876.96 & $<0.0001$ \\
\hline D-NPD & 0.5033 & 1 & 0.5033 & 236.19 & $<0.0001$ \\
\hline AB & 0.4761 & 1 & 0.4761 & 223.40 & $<0.0001$ \\
\hline AC & 0.2209 & 1 & 0.2209 & 103.65 & $<0.0001$ \\
\hline AD & 0.0256 & 1 & 0.0256 & 12.01 & 0.0035 \\
\hline BC & 0.8464 & 1 & 0.8464 & 397.16 & $<0.0001$ \\
\hline BD & 0.0009 & 1 & 0.0009 & 0.4223 & 0.5256 \\
\hline CD & 0.1156 & 1 & 0.1156 & 54.24 & $<0.0001$ \\
\hline$A^{2}$ & 0.1161 & 1 & 0.1161 & 54.47 & $<0.0001$ \\
\hline$B^{2}$ & 1.51 & 1 & 1.51 & 708.39 & $<0.0001$ \\
\hline$C^{2}$ & 0.9224 & 1 & 0.9224 & 432.82 & $<0.0001$ \\
\hline$D^{2}$ & 0.0088 & 1 & 0.0088 & 4.14 & 0.0600 \\
\hline Residual & 0.0320 & 15 & 0.0021 & & \\
\hline Lack of Fit & 0.0254 & 10 & 0.0025 & 1.92 & 0.2440 \\
\hline Pure Error & 0.0066 & 5 & 0.0013 & & \\
\hline Cor Total & 7.93 & 29 & & & \\
\hline
\end{tabular}

Table 4: Fitness of the developed model

\begin{tabular}{|l|r|l|r|}
\hline & & & \\
\hline Std. Dev. & 0.0462 & $\mathbf{R}^{2}$ & 0.9960 \\
\hline Mean & 0.9987 & Adjusted R & 0.9922 \\
\hline C.V. \% & 4.62 & Predicted $\mathbf{R}^{2}$ & 0.9853 \\
\hline & & Adeq Precision & 63.4051 \\
\hline
\end{tabular}




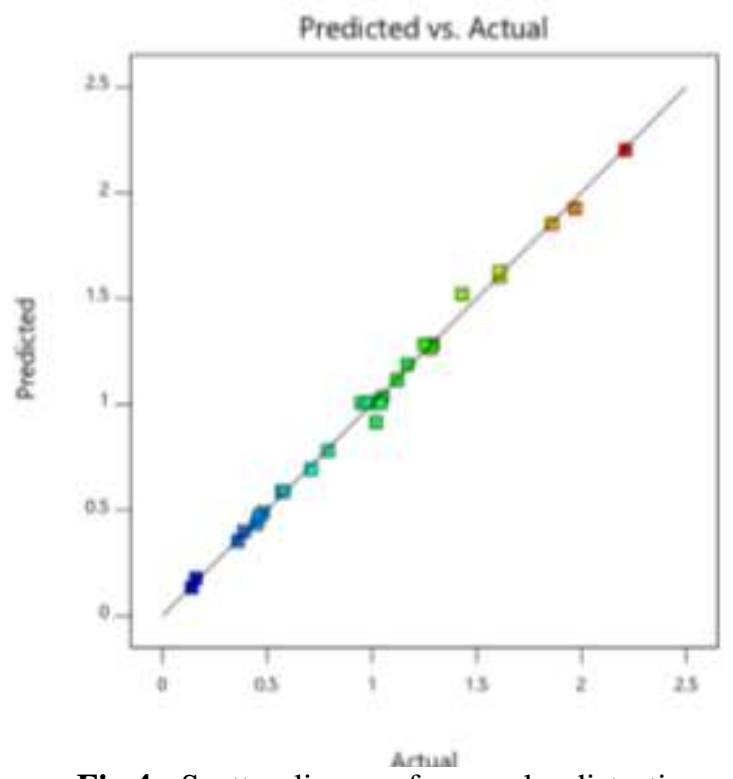

Fig 4 - Scatter diagram for angular distortion.

\section{RESULTS AND DISCUSSIONS}

The mathematical model given above can be used to predict the angular distortion by substituting the values of the respective process parameters. Also, the values of the process parameters can be obtained by substituting the value of allowable angular distortion values. The angular distortions calculated from the final model for each set of coded values of welding parameters are represented graphically in Figs. 5-9. These graphs generally show convincing trends between cause and effect. The direct effects and interaction effects are discussed below:

\subsection{Direct Effects of Process Parameters on}

\section{Angular Distortion}

The direct effects of process parameters on angular distortion are discussed below and presented in graphical form for better understanding. To keep the discussion within reasonable limits, only certain graphs have been shown and explained.

\subsubsection{Direct Effect of Nozzle to Plate Distance (NPD)}

From figure 7 , it can be observed that angular distortion increases with increase in NPD. When NPD increases, the length of wire coming out of the nozzle increases. This causes the current to follow through a larger distance, thereby increasing the resistance. The increased resistance adds to the heat which is reaching the weld joint.[8] This phenomenon is called resistive heating. Due to the increased heat, the angular distortion increases with increase in NPD.

\subsubsection{Direct Effect of Wire Feed Rate (WFR)}

From figure 6 , it is observed that angular distortion $(\alpha)$ increases with increase in WFR. This shows that WFR has a positive effect on $\alpha$. With increase in WFR, the welding current also increases. This increases the heat input to the weld which consequently increases the angular distortion.

\subsubsection{Direct Effect of Voltage on Angular Distortion}

Figure5 shows that angular distortion decreases with increase in voltage, but only up to a certain limit. After this threshold value of voltage, the distortion further increases with increase in voltage. This behavior can be explained on the basis of radiative loss due to heating. When voltage increases, arc length increases. The heat which is provided to the weld joint is lost due to the surroundings due to radiation. This decreases the heat input at the weld, resulting in decreased distortion. After a particular value of voltage, which is the threshold value ( 0.96 volts), the heat input due to increased arc length predominates over the radiative loss due to heating. The high heat then causes the angular distortion to increase further.

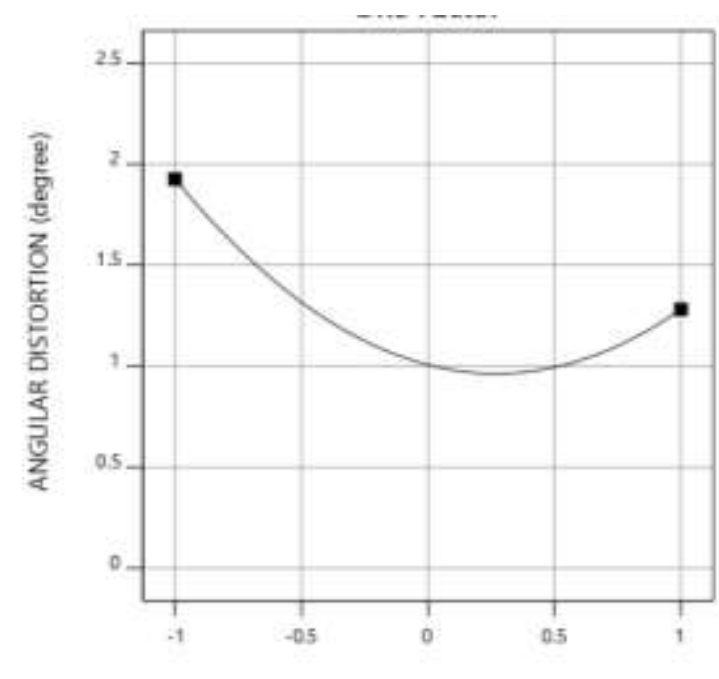

C. VOLTAGE $(\mathrm{M})$

Fig 5: Direct effect of voltage on angular distortion.

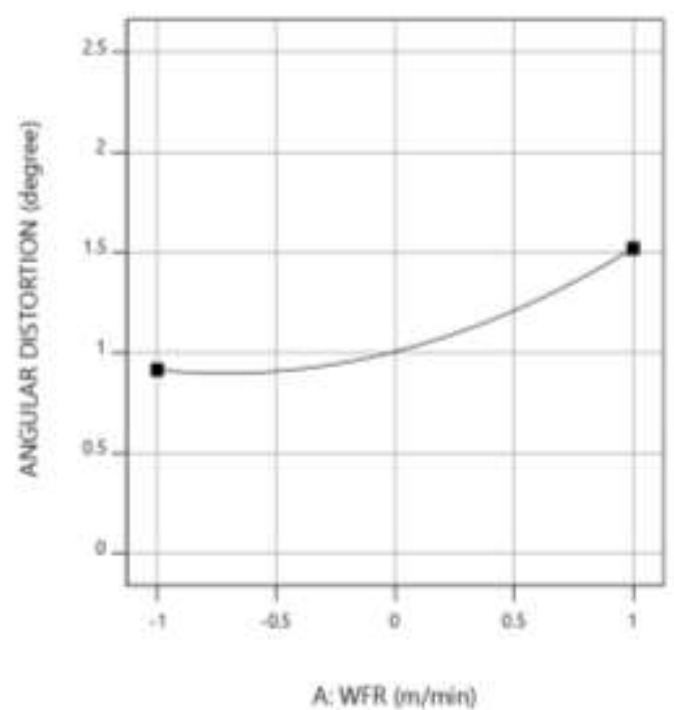

Fig 6: Direct effect of WFR on angular distortion. 


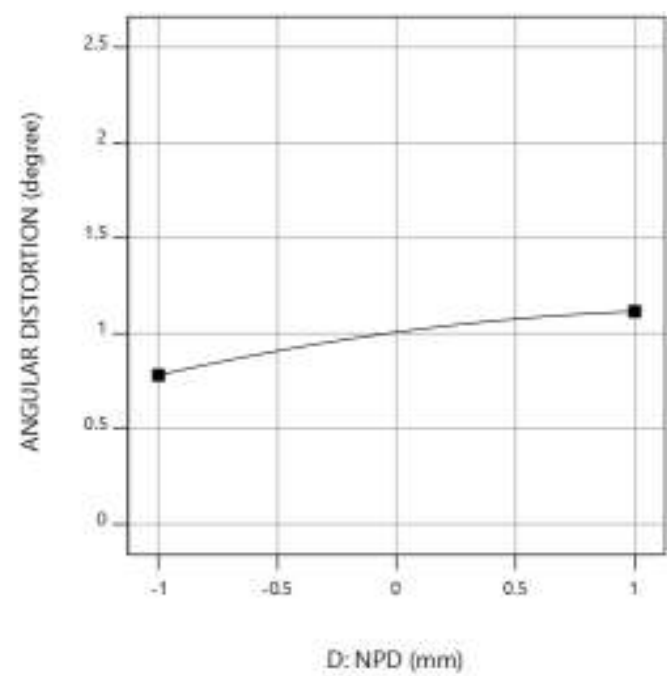

Fig 7: Direct effect of NPD on angular distortion.

\subsection{Interactive Effects of Process Variables on}

\section{Angular Distortion}

It is observed that the interaction of various parameters affects the behavior of one parameter when a second parameter is changed from one level to another level. The study of these interaction effects is very important to understand the sensitivity and integrity of the response behavior with the process control parameters. However, the interaction effect of several variables at a time can be extremely complicated to analyze and have little significance. Hence, to keep the discussion within reasonable limits, only the important interaction effects have been discussed along with their three-dimensional contour plots.

\subsubsection{Interaction effect of WFR and NPD on}

\section{Angular Distortion}

It was seen earlier that with increase in NPD and WFR, angular distortion increases. The combined effect of these two factors also shows a similar behavior when the other two factors (voltage and welding speed) are kept constant, as shown in figure 8. Angular distortion increases with increase in WFR for all values of NPD and vice versa. The increase in welding current due to increasing WFR, coupled with the resistive heating of the wire due to increase in NPD causes an overall increase in the heat input. This increased heat input causes the metal pieces to be distorted further.

\subsubsection{Interaction Effect of Voltage and WFR on}

\section{Angular Distortion}

From figure 9, it is observed that with increase in WFR angular distortion increases for all values of voltage. But with increase in voltage angular distortion first decreases and then increases for all values of WFR. When WFR increases, current increases which increases the depth of penetration of heat thus angular distortion increases. And when voltage increases, arc length increases which spreads the arc and penetration of heat decreases, hence decreases the angular distortion.

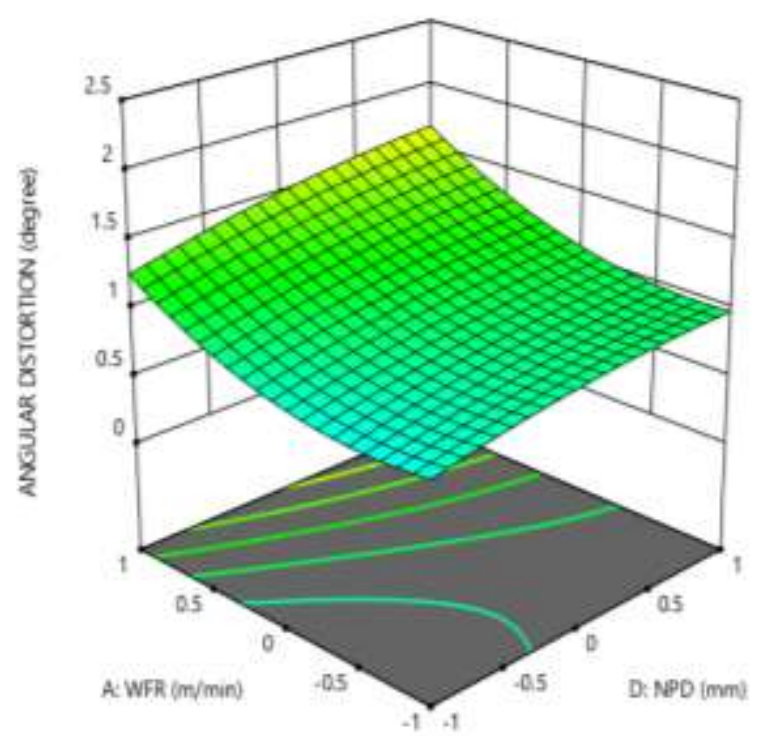

Fig 8: Interaction effect of WFR and NPD on angular distortion

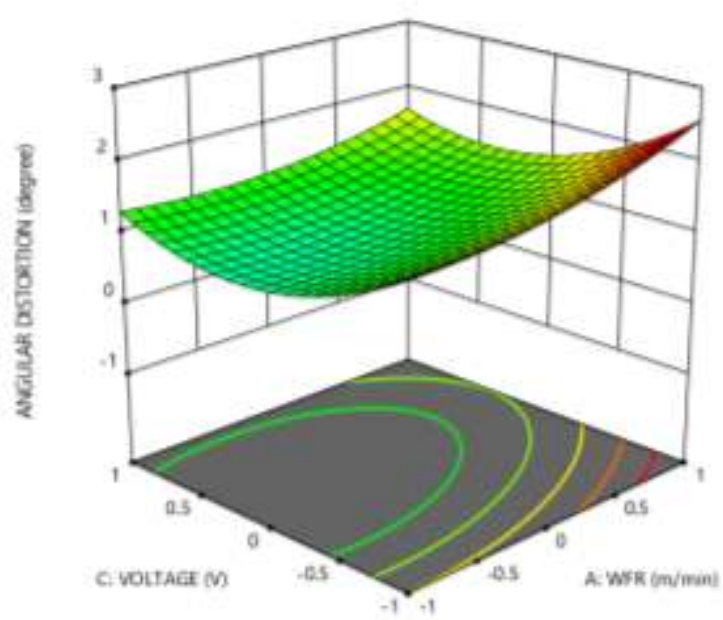

Fig 9: Interaction effect of Voltage and WFR on angular distortion

\section{CONCLUSION}

The following conclusions were arrived at from this investigation:

a) The central composite response surface design and the second order quadratic mathematical model was useful in determining the angular distortion of MAG welds.

b) Welding voltage has a strong effect on angular distortion. It has a negative effect on angular distortion at lower values whereas the effect is positive at higher values.

c) NPD and WFR have positive effects on angular distortion. 


\section{REFERENCES}

[1] Applied metallurgy, Lecture 2.6: Welding of Structural Steel.http://fggweb.fgg.unilj.si/ /pmoze/esdep/master/wg02/10600.ht $\mathrm{m}$, accessed on 19-06-2018.

[2] Jeff Nadzam, "Gas Metal Arc Welding, Product and Procedure selection", Lincoln Electric, August 2014. Retrieved from www.lincolnelectric.com

[3] Ramani. S and Velmurugan. V, "Effect of Process Parameters on Angular distortion of MIG welded AI6061 plates", $5^{\text {th }}$ and $26^{\text {th }}$ All India Manufacturing Technology, Design and Research Conference (AIMTDR 2014), IIT Guwahati, Assam

[4] V. Gunarajan and N. Murugan, "Application of Response surface methodology for predicting weld bead quality in submerged arc welding of pipes", Journal of Materials Processing Technology 88(1-3): 266-275, April 1999.

[5] V. Gunarajan and N. Murugan, "Prediction and optimization of weld bead volume for the submerged arc process- Part 2", Welding Research Supplement: $331-s$, November 2000.

[6] N. Murugan and R.S. Parmar, "Effects of MIG Process Parameters on the geometry of the bead in the Automatic surfacing of Stainless Steel", Journal of Materials Processing Technology 41(4): 381-398, March 1994

[7] Gunaraj, V., and Murugan, N. 2002. Prediction of heat-affected zone characteristics in submerged arc welding of structural steel plates. Welding Journal 81(3): 45 -s to 53 -s.

[8] Hirai, S., and Nakamura, I. 1955. Research on angular change in fillet welds, Ishikawajima Review, pp. 59-68.

\section{BIOGRAPHIES}

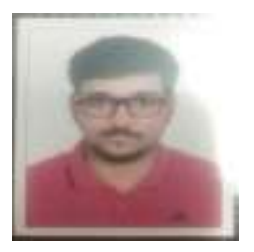

Rishav is pursuing his 2nd year of UG course in manufacturing processes and automation engineering

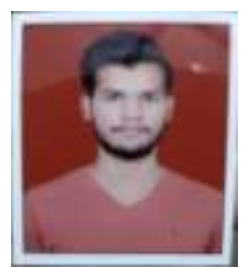

Ajay is pursuing his 2nd year of UG course in manufacturing processes and automation engineering

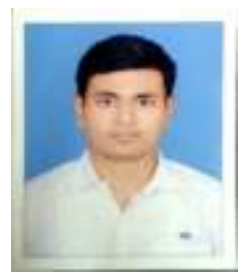

Anubhav is pursuing his 2 nd year of UG course in manufacturing processes and automation engineering

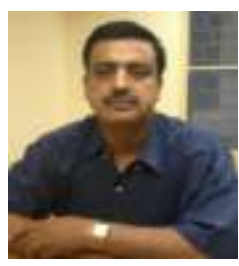

Pradeep Khanna is an associate professor in the division of manufacturing processes and automation engineering 